\title{
Article \\ Eccentric Cycling Training Improves Erythrocyte Antioxidant and Oxygen Releasing Capacity Associated with Enhanced Anaerobic Glycolysis and Intracellular Acidosis
}

\author{
Yu-Chieh Huang ${ }^{1}{ }^{(D}$, Mei-Ling Cheng ${ }^{2,3,4} \mathbb{D}$, Hsiang-Yu Tang ${ }^{2} \mathbb{D}$, Chi-Yao Huang ${ }^{5}$, Kuan-Ming Chen ${ }^{5}$ and \\ Jong-Shyan Wang $5,6,7, *$
}

check for

updates

Citation: Huang, Y.-C.; Cheng, M.-L.; Tang, H.-Y.; Huang, C.-Y.; Chen, K.-M.; Wang, J.-S. Eccentric Cycling Training Improves Erythrocyte Antioxidant and Oxygen Releasing Capacity Associated with Enhanced Anaerobic Glycolysis and Intracellular Acidosis. Antioxidants 2021, 10, 285. https://doi.org/ $10.3390 /$ antiox10020285

Academic Editor: Gareth Davison and Conor McClean

Received: 25 January 2021

Accepted: 10 February 2021

Published: 13 February 2021

Publisher's Note: MDPI stays neutral with regard to jurisdictional claims in published maps and institutional affiliations.

Copyright: (c) 2021 by the authors. Licensee MDPI, Basel, Switzerland. This article is an open access article distributed under the terms and conditions of the Creative Commons Attribution (CC BY) license (https:// creativecommons.org/licenses/by/ $4.0 /)$.
1 Department of Physical Therapy, College of Medical and Health Science, Asia University, Taichung 413, Taiwan; yuchieh@asia.edu.tw

2 Metabolomics Core Laboratory, Healthy Aging Research Center, Chang Gung University, Taoyuan 333, Taiwan; chengm@mail.cgu.edu.tw (M.-L.C.); tangshyu@gmail.com (H.-Y.T.)

3 Clinical Metabolomics Core Laboratory, Chang Gung Memorial Hospital, Taoyuan 333, Taiwan

4 Department of Biomedical Sciences, College of Medicine, Chang Gung University, Taoyuan 333, Taiwan

5 Healthy Aging Research Center, Graduate Institute of Rehabilitation Science, Medical Collage, Chang Gung University, Taoyuan 333, Taiwan; kjes9210@hotmail.com (C.-Y.H.); ttlike76@gmail.com (K.-M.C.)

6 Heart Failure Center, Department of Physical Medicine and Rehabilitation, Keelung Chang Gung Memorial Hospital, Keelung 204, Taiwan

7 Research Center for Chinese Herbal Medicine, College of Human Ecology, Chang Gung University of Science and Technology, Taoyuan 333, Taiwan

* Correspondence: s5492@mail.cgu.edu.tw; Tel.: +886-3-2118800 (ext. 5748); Fax: +886+886-3-2118700

Abstract: The antioxidant capacity of erythrocytes protects individuals against the harmful effects of oxidative stress. Despite improved hemodynamic efficiency, the effect of eccentric cycling training (ECT) on erythrocyte antioxidative capacity remains unclear. This study investigates how ECT affects erythrocyte antioxidative capacity and metabolism in sedentary males. Thirty-six sedentary healthy males were randomly assigned to either concentric cycling training (CCT, $n=12)$ or ECT $(n=12)$ at $60 \%$ of the maximal workload for $30 \mathrm{~min} /$ day, 5 days/week for 6 weeks or to a control group $(n=12)$ that did not receive an exercise intervention. A graded exercise test (GXT) was performed before and after the intervention. Erythrocyte metabolic characteristics and $\mathrm{O}_{2}$ release capacity were determined by UPLC-MS and high-resolution respirometry, respectively. An acute GXT depleted Glutathione (GSH), accumulated Glutathione disulfide (GSSG), and elevated the GSSG/GSH ratio, whereas both CCT and ECT attenuated the extent of the elevated GSSG/GSH ratio caused by a GXT. Moreover, the two exercise regimens upregulated glycolysis and increased glucose consumption and lactate production, leading to intracellular acidosis and facilitation of $\mathrm{O}_{2}$ release from erythrocytes. Both CCT and ECT enhance antioxidative capacity against severe exercise-evoked circulatory oxidative stress. Moreover, the two exercise regimens activate erythrocyte glycolysis, resulting in lowered intracellular $\mathrm{pH}$ and enhanced $\mathrm{O}_{2}$ released from erythrocytes.

Keywords: eccentric exercise; redox status; erythrocyte; metabolism

\section{Introduction}

Endurance training is essential to maximally improve cardiopulmonary fitness and delay the disease process. However, this may be intolerable due to the overload of the cardiopulmonary system to elderly individuals or patients with chronic diseases, traditional concentric work at usual training intensity [1]. Eccentric endurance training has the ability to overcome these limitations because of less respiratory requirement and metabolic oxygen, as well as lower heart rate $(\mathrm{H})$, cardiac index and blood lactate concentration than concentric type at equivalent workload [2]. The benefits of using eccentric cycling training (ECT) in chronic heart failure patients [3], elderly individuals [4] and chronic obstructive 
pulmonary disease [5] have been confirmed. Conventionally, most studies have focused on the contribution to elicit neuromuscular adaptations of eccentric work [6]; nevertheless, a recent study further demonstrated that either acute bout of concentric or eccentric cycling at moderate intensity induced increased enzymatic antioxidant capacity and decreased oxidative stress markers [7]. Moreover, ECT induces greater fat utilization compared to concentric cycling training (CCT) at a fixed workload [8] and greater fat loss in obese adolescents [9]. Therefore, the different cardiopulmonary loading and metabolic oxygen demands in ECT and CCT may result in distinct changes in antioxidative metabolism and $\mathrm{O}_{2}$ release adaptations [10]. However, there is very limited evidence regarding these mechanisms of chronic physiological responses to eccentric cycling [11].

Erythrocytes are vital to humans because of their abundance and the irreplaceable function they have of delivering $\mathrm{O}_{2}$. However, they are susceptible to sustained free radical damage during circulation, which impairs their $\mathrm{O}_{2}$ release capacity and reduces their lifespan [12]. Previous studies have reported that blood antioxidation capacity is impaired with acute exercise [13]; in contrast, regular exercise may increase antioxidative capacity [14]. The lower oxygen and energy consumed in ECT may avoid repeated, excessive exposure to oxidative stress, which progressively impair the erythrocyte [15]. However, whether this lower metabolic stress in comparable ECT might be enough to elicit physiological adaptations as CCT or not is another concern [16]. To date, the adaptations of the antioxidation capacity and regulatory mechanism of erythrocytes under different exercise regimens remain unclear. Here, we identified the key regulatory mechanisms using metabolomics profiling technology.

When exercising, erythrocytes must accelerate $\mathrm{O}_{2}$ release into peripheral tissue according to the Bohr effect [17] and enhance the demand for glycolytically derived ATP to restore intracellular ion balances. This process is at a constant rate when ATP consumption is steady, but the activity of the process changes rapidly in response to enhanced ATP utilization [18]. Importantly, erythrocytes are also exposed to dramatically enhanced oxidative stress that must be controlled by accelerated production of reducing equivalents derived from the pentose phosphate pathway (PPP), which is the sole source of NADPH and produces GSH as an antioxidant. In the sickle cells, the impaired antioxidant capacity leaves to a loss of glycolysis and the PPP shifting mechanism control and further homeostasis rupture, contributing to a decreased lifespan of cells [19]. Moreover, altering glycolytic pathway dominance has been demonstrated to limit antioxidation capacity under hypoxia [20]. Therefore, exercise may introduce continuous substrate competition between the main glycolysis pathway and the PPP, although this needs to be further elucidated.

2,3-BPG is a strong allosteric modulator that leads to $\mathrm{O}_{2}$ unloading [21]. However, the generation of 2,3-BPG bypasses the main phosphoglycerate kinase reaction so that the overall production of ATP per mole of glucose is decreased to zero. GSH de novo synthesis is ATP dependent and is therefore impaired when the stocks of intracellular ATP are depleted. In addition, lactate is the only end product of glycolysis in erythrocytes, and it also helps create a low $\mathrm{pH}$ value environment to decrease $\mathrm{Hb}-\mathrm{O}_{2}$ affinity [22] and influence GSH synthesis [23]. Therefore, one of the biggest puzzles regarding erythrocyte metabolism during exercise is how the programming of erythrocyte glucose metabolism, 2,3-BPG production, and antioxidative capacity is regulated.

To address the abovementioned questions, this study elucidated the pathways underlying the regulation of the main glycolysis and the PPP and explored the effects of oxidation and antioxidation capacity in erythrocytes after six weeks of interventions. In addition, we also investigated the capacity for $\mathrm{O}_{2}$ release under different lactate concentrations under hypoxic and normoxic conditions. The aim of this study was to provide direct evidence that both ECT and CCT induce metabolic adaptations within erythrocytes that counteract the high oxidative stress evoked by vigorous exercise. 


\section{Materials and Methods}

\subsection{Subjects}

The intervention was performed in accordance with the Declaration of Helsinki and was approved by the Institutional Review Board of Chang Gung Memorial Hospital in Taiwan. A total of 36 sedentary males who were nonsmokers, nonusers of medication/vitamins, and free of any cardiopulmonary/hematological risks were recruited from Chang Gung University, Taiwan. No subject had performed regular exercise (i.e., exercise frequency once per week, duration $<20 \mathrm{~min}$ ) for at least 1 year before the experiment. All subjects provided informed consent after the experimental procedures were explained. These subjects were randomly divided into three groups: the concentric cycling training $(\mathrm{CCT}, n=12)$, the eccentric cycling training (ECT, $n=12)$, and the control (CTL, $n=12)$ groups. All subjects arrived at the testing center at 9:00 AM to eliminate any possible circadian effect. Participants were instructed to fast for at least $8 \mathrm{~h}$ and to refrain from strenuous physical exercise for at least $48 \mathrm{~h}$ before sampling.

\subsection{Protocol and Interventions}

Both the CCT and ECT groups performed exercise regimens on a stationary bicycle ergometer (CCT: Corival 400, Lode; ECT: custom-built cycle ergometer) 5 times a week for 6 weeks. For comparison, the CTL group did not perform any exercise, but their physical activities and daily diet were carefully documented.

All subjects reported their daily activities and nutrition intakes via questionnaires throughout the experiment. The participants were instructed to refrain from extra regular exercise until the end of this study. Moreover, the compliance rates for all three interventions were $100 \%$.

The graded exercise test (GXT) was performed $48 \mathrm{~h}$ before and after the intervention. Both the CCT and ECT groups had a 3 day familiarization program upon initiation of training. The exercise intensity was set at $20 \%, 30 \%$, and $40 \%$ of the maximal workload $\left(\mathrm{W}_{\max }\right)$ on each day. The first week's intensity was set at $45 \% \mathrm{~W}_{\max }$ and progressively increased $5 \% \mathrm{~W}_{\max }$ per week until 70\% $\mathrm{W}_{\max }$ was obtained in the sixth week. Each training session contained a 6 -min warm-up phase ( $3 \mathrm{~min}$ at $0 \%$ and $3 \mathrm{~min}$ at $30 \% \mathrm{~W}_{\max }$ ), 30-min training period and 6-min cool-down phase ( $3 \mathrm{~min}$ at $30 \%$ and $3 \mathrm{~min}$ at $0 \% \mathrm{~W}_{\max }$ ) (Figure 1 ). The training groups were asked to record their daily activities and nutritional intake using the short form of the international physical activity questionnaire and a written diet record, respectively. Subjects were asked to refrain from regular extra exercise until the end of the study. The participant compliance rate was $100 \%$ throughout this study. 


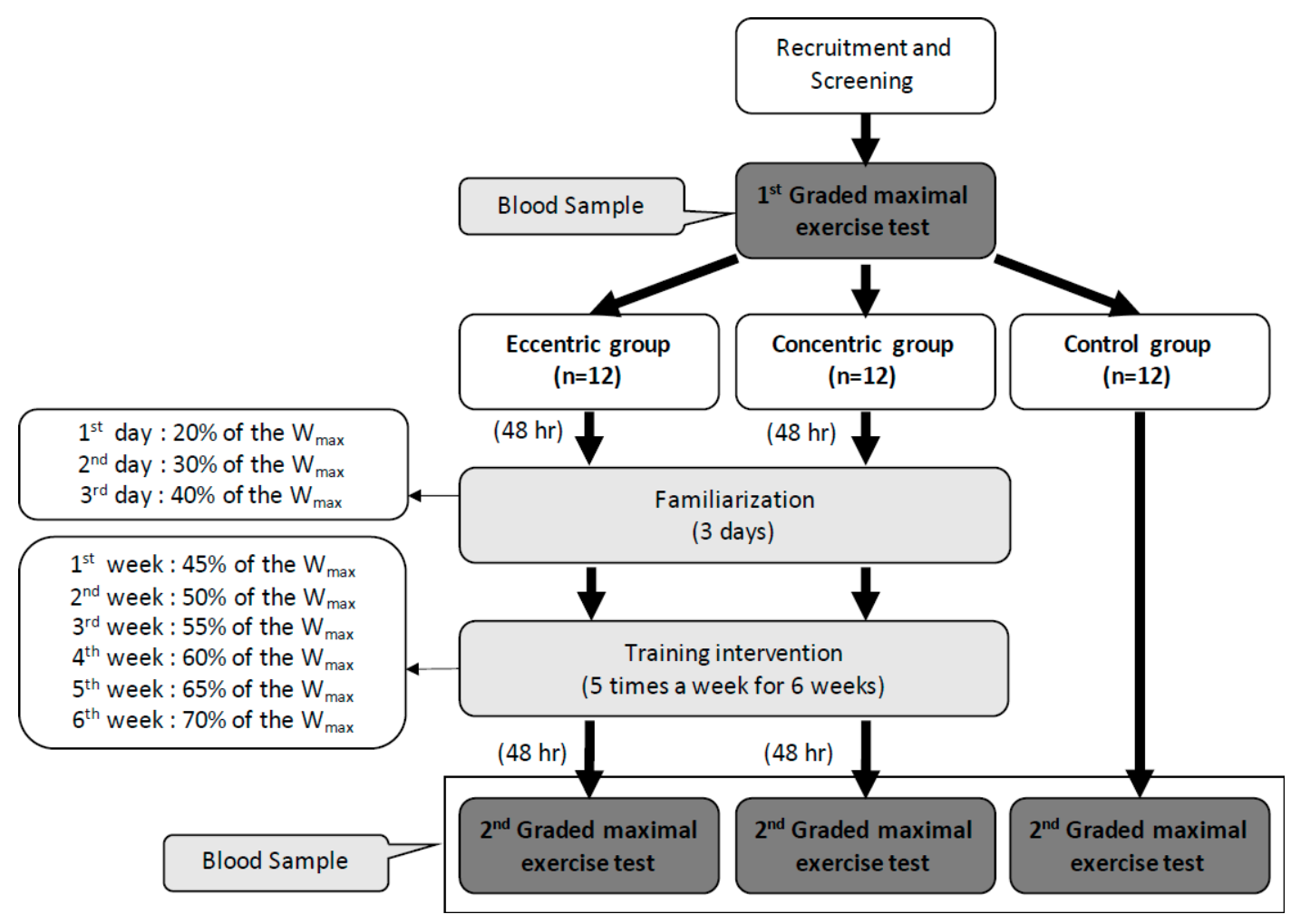

Figure 1. Design of the experiment and the training intensity of eccentric and concentric groups in each week. $W_{\text {max }}$ : the maximal workload of the first graded maximal exercise test.

\subsection{Graded Exercise Tests}

To assess aerobic capacity, a GXT was performed on a cycle ergometer (Corival 400, Lode B.V., Groningen, The Netherlands). After a 5-min baseline resting period, a 2-min warm-up period (60 rpm, unloaded pedaling) was initiated, followed by incremental work (30 Watt increase for each $3 \mathrm{~min}$ ) until exhaustion (i.e., progressive exercise to $\mathrm{VO}_{2 \max }$ ). Minute ventilation $\left(\mathrm{V}_{\mathrm{E}}\right)$, oxygen consumption $\left(\mathrm{VO}_{2}\right)$, and carbonic dioxide production $\left(\mathrm{VCO}_{2}\right)$ were measured for each breath by using a computer-based system (MasterScreen $\mathrm{CPX}$, CareFusion, Franklin Lakes, NJ, USA). The criteria used to define $\mathrm{VO}_{2 \max }$ were as follows: (i) the level of $\mathrm{VO}_{2}$ increased by $<2 \mathrm{~mL} / \mathrm{kg} / \mathrm{min}$ over at least $2 \mathrm{~min}$; (ii) H exceeded its predicted maximum; (iii) the respiratory exchange ratio (RER) exceeded 1.2; and (iv) the venous lactate concentration was $>8 \mathrm{mM}$, which was consistent with the guidelines of the American College of Sports Medicine for exercise testing [24]. Additionally, the ventilation threshold (VT) was determined when $\mathrm{VE} / \mathrm{VO}_{2}$ increased without a corresponding increase in the $\mathrm{V}_{\mathrm{E}}$-to- $\mathrm{VCO}_{2}$ ratio and when end-tidal $\mathrm{PO}_{2}$ increased without a decrease in end-tidal $\mathrm{PCO}_{2}$ or a deviation from linearity for $\mathrm{V}_{\mathrm{E}}$.

\subsection{Erythrocyte Isolation and Blood Collection}

At rest and immediately after the GXT, a $10 \mathrm{~mL}$ blood sample was collected from the antecubital vein via clean venipuncture (20-gauge needle) and added to a tube with ethylenediaminetetraacetic acid (EDTA, $4 \mathrm{mM}$ ). Blood cells were counted by using a Sysmex SF-3000 cell counter (GMI Inc., Ramsey, MN, USA), and the blood pH and lactate concentration were tested by an i-STAT handheld blood analyzer (Abbott Point of Care Inc., Princeton, NJ, USA). Erythrocytes were isolated from whole blood by centrifugation $(1000 \times g$ for $15 \mathrm{~min}$ at RT), the supernatant was discarded, and the buffy coat was discarded, followed by three washing steps in PBS with $0.1 \%(w / v)$ glucose (Sigma). The erythrocyte count was adjusted to $1 \times 10^{4}$ cells $/ \mu \mathrm{L}$ using PBS. 


\subsection{Measurement of Reactive Oxygen Species (ROS) Production}

$2^{\prime}, 7^{\prime}$-Dichlorofluorescin diacetate (DCFDA) is a fluorogenic dye that measures hydroxyl, peroxyl and other ROS activities within the cell. This study used a DCFDA Cellular ROS Detection Assay Kit (ab113851, Abcam) to measure intracellular ROS according to the manufacturer's protocol. DCFDA-labeled erythrocytes were treated with different concentrations of tert-butyl hydroperoxide (TBHP) $(5 \mathrm{mM}, 10 \mathrm{mM}, 50 \mathrm{mM}$ and $100 \mathrm{mM})$ at $37^{\circ} \mathrm{C}$ for $30 \mathrm{~min}$. TBHP mimics ROS activity to oxidize DCFDA to fluorescent DCF. Finally, the mean fluorescence intensities obtained from 50,000 erythrocytes were measured using FACSCalibur (Becton Dickinson, NJ, USA). All samples were analyzed in triplicate, and the intraassay $\mathrm{CV}$ was $4.1 \pm 0.7 \%$.

\subsection{Erythrocyte Intracellular $p H$}

As our previous study presented [25], erythrocytes were loaded with the fluorescent $\mathrm{pH}$ indicator carboxy SNARF- $1(1 \mu \mathrm{M}$, Invitrogen $)$ at $37^{\circ} \mathrm{C}$ for $30 \mathrm{~min}$ in the dark and then washed with HBSS (Sigma) at $2500 \times g$ for $5 \mathrm{~min}$. SNARF-1-loaded cells were incubated with pH-controlled normal $\mathrm{K}^{+}$-balanced buffer $(137.9 \mathrm{mM} \mathrm{NaCl}, 5.33 \mathrm{mM} \mathrm{KCl}, 0.441 \mathrm{mM}$ $\mathrm{KH} 2 \mathrm{PO} 4,4.17 \mathrm{mM} \mathrm{NaHCO} 3,0.338 \mathrm{mM} \mathrm{Na} 2 \mathrm{HPO} 4,5.56 \mathrm{mM}$ glucose, and $20 \mathrm{mM}$ HEPES, $\mathrm{pH}=7.5)$ and high $\mathrm{K}^{+}$-balanced buffer at different $\mathrm{pH}$ values $(43.7 \mathrm{mM} \mathrm{NaCl}, 100 \mathrm{mM} \mathrm{KCl}$, $0.441 \mathrm{mM}$ KH2PO4, $4.17 \mathrm{mM} \mathrm{NaHCO} 3,0.338 \mathrm{mM} \mathrm{Na} 2 \mathrm{HPO} 4,5.56 \mathrm{mM}$ glucose, and $20 \mathrm{mM}$ HEPES, $\mathrm{pH}=6.8,7.0,7.2,7.4,7.6,7.8$, and 8.0) containing $10 \mu \mathrm{M}$ nigericin (Invitrogen). The $\mathrm{pH}$ was always adjusted at $\mathrm{RT}$ prior to use. The $\mathrm{pH}$-dependent spectral shifts exhibited by SNARF-1 allowed calibration of the $\mathrm{pH}$ response in terms of the ratio of fluorescence intensities measured at two different wavelengths, FL2 and FL3, in a FACSCalibur $(\lambda 1=580 \mathrm{~nm}$ and $\lambda 2=600 \sim 640 \mathrm{~nm}$ and fixed excitation at $514 \mathrm{~nm}$ ), as described in the manufacturer's protocol (Invitrogen). All samples were analyzed in triplicate, and the intraassay CV was $3.7 \pm 0.9 \%$. The equation is as follows:

$$
\mathrm{pH}=\mathrm{pK}_{\mathrm{a}}-\log _{10}\left[\frac{\mathrm{R}-\mathrm{R}_{\mathrm{B}}}{\mathrm{R}_{\mathrm{A}}-\mathrm{R}} \times \frac{\mathrm{F}_{\mathrm{B}(\lambda 2)}}{\mathrm{F}_{\mathrm{A}(\lambda 2)}}\right]
$$

pKa values: 7.5 for carboxy SNARF-1;

$R$ : The ratio $F \lambda 1 / F \lambda 2$ of fluorescence intensities $(F)$ measured at $\lambda 1$ and $\lambda 2$;

The subscript A represents the limiting values at the acidic endpoints of the titration;

The subscript $B$ represents the limiting values at the basic endpoints of the titration.

\subsection{Oxygen Release Efficacy in Erythrocytes}

High-resolution respirometry, an Oroboros Oxygraph-2 K (Oroboros Instruments, Innsbruck, Austria), was used to measure the $\mathrm{O}_{2}$ pressure $(\mathrm{mmHg})$ and $\mathrm{O}_{2}$ flux per volume $\left(\mathrm{pmol} \cdot \mathrm{s}^{-1} \cdot \mathrm{mL}^{-1}\right.$ ) of erythrocytes at $0-, 1-$, and $4 \mathrm{mM}$ lactate during hypoxia $\left(\mathrm{PO}_{2}=20 \pm 3 \mathrm{mmHg}\right)$ and normoxia $\left(\mathrm{PO}_{2}=147 \pm 3 \mathrm{mmHg}\right)$ in HBSS medium, respectively. Hypoxic conditions were prepared by gassing with nitrogen $\left(\mathrm{N}_{2}\right)$ gas. After heating at $37^{\circ} \mathrm{C}$ and equilibration and calibration for the target $\mathrm{PO}_{2}$ conditions, $2 \times 10^{6}$ isolated erythrocytes were added, and after the signaling stabilized, 2 and $6 \mu \mathrm{L}$ of $1 \mathrm{M}$ lactic acid (Sigma) were sequentially added to form 1 and $4 \mathrm{mM}$ lactic acid environments to simulate the rest and lactate threshold conditions, respectively (Figure S1). All samples were analyzed in triplicate, and the intraassay $\mathrm{CV}$ was $3.9 \pm 0.8 \%$. 


\subsection{Sample Preparation for Targeted Metabolite Identification and Quantification}

Fifteen randomly selected samples $(E C T=5, C C T=5$, and $C T L=5)$ were quantified for the target metabolite. Erythrocytes $\left(6 \times 10^{8}\right)$ were lysed in $200 \mu \mathrm{L}$ of dd $\mathrm{H}_{2} \mathrm{O}$ containing $100 \mathrm{ppb}$ of debrisoquine sulfate (Sigma) as an internal control. The lysate was extracted in $800 \mu \mathrm{L}$ of warmed methanol. The sample was incubated at RT for $15 \mathrm{~min}$ to precipitate proteins and centrifuged at $16,000 \times \mathrm{g}$ for $30 \mathrm{~min}$ at $4{ }^{\circ} \mathrm{C}$. The supernatant was transferred to a new tube, dried under nitrogen gas, and stored at $-80^{\circ} \mathrm{C}$. Prior to analysis, the sample was dissolved in $200 \mu \mathrm{L}$ of $\mathrm{ddH}_{2} \mathrm{O}$ containing $0.1 \%$ formic acid. The procedure was carried out according to the method of Tang et al. [26].

\subsection{Target Metabolite Analysis of Glycolysis Intermediates}

All samples were analyzed using ultrahigh-performance liquid chromatography (UHPLC) coupled with Xevo TQ-S MS (Waters Corp., MA USA) as previously described with modifications [27]. MS was performed in negative-ion multiple-reaction-monitoring (MRM) mode. For tuning purposes, a single analysis standard dissolved in a mixture of water/methanol 50:50 (v/v) was infused at a flow rate of $10 \mu \mathrm{L} / \mathrm{min}$. The desolvation gas flow was set at $1000 \mathrm{~L} / \mathrm{h}$ at a temperature of $500{ }^{\circ} \mathrm{C}$, and the source temperature was set at $150{ }^{\circ} \mathrm{C}$. The capillary voltage and cone voltage were set to $1.3 \mathrm{kV}$ and $25 \mathrm{~V}$, respectively. For chromatographic separation, a BEH C18 $(100 \mathrm{~mm} \times 2.1 \mathrm{~mm}, 1.7 \mu \mathrm{m}$; Waters Corp, MA, USA) was used with eluent $A(10 \mathrm{mM}$ tributylamine aqueous solution with $15 \mathrm{mM}$ acetic acid) and eluent $B(50 \%$ acetonitrile containing $10 \mathrm{mM}$ tributylamine and $15 \mathrm{mM}$ acetic acid), the flow rate was $0.3 \mathrm{~mL} / \mathrm{min}$, and the column temperature was set at $25^{\circ} \mathrm{C}$. The gradient profile was as follows: linear-gradient $99-98 \%$ solvent $\mathrm{B}, 8 \mathrm{~min} ; 12 \%$ solvent $\mathrm{B}, 2 \mathrm{~min}$; $55 \%$ solvent B, $2 \mathrm{~min}$; and $99 \%$ solvent B, 2 min. The column was then re-equilibrated for $4 \mathrm{~min}$. QC samples were analyzed during the analytical runs. All samples were analyzed in triplicate, and the intraassay CV was $3.4 \pm 0.6 \%$.

\subsection{Senescence-Related Biological Markers and Methemoglobin Concentrations in Erythrocytes}

The erythrocyte suspension $\left(1 \times 10^{4}\right.$ cells $\left./ \mu \mathrm{L}\right)$ was incubated with saturating concentrations of monoclonal anti-human CD47 antibody (BioLegend) or monoclonal anti-human CD147 antibody (eBioscience) conjugated with fluorescein isothiocyanate (FITC) in the dark for $30 \mathrm{~min}$ at $37^{\circ} \mathrm{C}$. The mean fluorescence intensity (MFI) obtained from 50,000 erythrocytes was measured by a FACSCalibur (Becton Dickinson, NJ USA). Human methemoglobin (met-Hb) ELISA kit (CSB-E09493 h, CUSABIO, Huston, TX USA) obtained from CUSABIO was used according to the manufacturers' instructions. All samples were analyzed in triplicate, and the intraassay CV was $4.4 \pm 0.7 \%$.

\subsection{Statistical Analysis}

Data were analyzed using the statistical software SPSS 22.0 (SPSS, Chicago, IL USA), and continuous data are expressed as the means \pm SEM. Nonparametric results were examined by the Mann-Whitney $U$ test and Wilcoxon signed ranked test. Parametric results were tested by two-way repeated-measures ANOVA (group $\times$ time points) and the Newman-Keuls post hoc test to identify significant changes pre- vs. postintervention and pre- vs. post-graded exercise tests. Correlations were measured by Pearson's correlation coefficient. The level of statistical significance was $p<0.05$. 


\section{Results}

\subsection{Cardiopulmonary Fitness and Hematological and Blood Gas Parameters}

There were no differences in anthropometric characteristics, hematological parameters, blood $\mathrm{pH}$, lactate concentration or exercise performance among the groups at baseline (Table 1). Following 6 weeks of training, both the CCT and ECT groups demonstrated increases in work rate, $\mathrm{VE}$, and $\mathrm{VO}_{2}$ at the ventilation threshold (VT). Moreover, CCT was superior to ECT for enhancing the work rate and $\mathrm{VO}_{2}$ at VT. At the peak performance, only CCT enhanced the VEmax and $\mathrm{VO}_{2}$ max, while ECT only resulted in an improvement in the work rate (Table 1). However, 6 weeks of the CTL did not influence hematological parameters or cardiopulmonary responses to a GXT (Table 1).

Table 1. Anthropometric data and ventilatory responses to graded exercise test in concentric and eccentric training groups.

\begin{tabular}{|c|c|c|c|c|c|c|c|}
\hline & & \multicolumn{2}{|c|}{ CCT } & \multicolumn{2}{|c|}{ ECT } & \multicolumn{2}{|c|}{ CTL } \\
\hline & & Pre & Post & Pre & Post & Pre & Post \\
\hline \multicolumn{8}{|c|}{ Anthropometrics Characteristics } \\
\hline Age, year & & $21.3 \pm 0.5$ & - & $21.7 \pm 0.4$ & - & $21.6 \pm 0.6$ & - \\
\hline Height, $\mathrm{cm}$ & & $174 \pm 1$ & - & $173 \pm 2$ & - & $175 \pm 1$ & - \\
\hline Weight, $\mathrm{kg}$ & & $67.5 \pm 2.3$ & $68.4 \pm 1.9$ & $68.1 \pm 1.3$ & $67.4 \pm 1.5$ & $67.2 \pm 2.2$ & $68.0 \pm 2.2$ \\
\hline \multicolumn{8}{|c|}{ Hematological Parameters } \\
\hline Red blood ce & $/ \mu \mathrm{L}$ & $5.10 \pm 0.08$ & $5.05 \pm 0.05$ & $5.13 \pm 0.06$ & $5.06 \pm 0.07$ & $5.13 \pm 0.06$ & $5.13 \pm 0.07$ \\
\hline $\mathrm{Hb}, \mathrm{g} / \mathrm{dL}$ & & $14.9 \pm 0.2$ & $14.5 \pm 0.2$ & $15.0 \pm 0.4$ & $14.9 \pm 0.3$ & $15.0 \pm 0.3$ & $14.7 \pm 0.3$ \\
\hline Hematocrit, \% & & $45.4 \pm 0.7$ & $44.5 \pm 0.6$ & $46.2 \pm 0.6$ & $45.3 \pm 0.6$ & $46.2 \pm 0.6$ & $45.2 \pm 0.5$ \\
\hline \multicolumn{8}{|l|}{ i-STAT Parameters } \\
\hline \multirow[t]{2}{*}{ Blood $\mathrm{pH}$, unit } & Rest & $7.37 \pm 0.02$ & $7.37 \pm 0.01$ & $7.36 \pm 0.01$ & $7.37 \pm 0.01$ & $7.36 \pm 0.02$ & $7.35 \pm 0.01$ \\
\hline & Ex & $7.23 \pm 0.02 \#$ & $7.21 \pm 0.02 \#$ & $7.19 \pm 0.01 \#$ & $7.19 \pm 0.01 \#$ & $7.19 \pm 0.03 \#$ & $7.19 \pm 0.02 \#$ \\
\hline \multirow{2}{*}{ Blood lactate, $\mathrm{mM}$} & Rest & $0.88 \pm 0.11$ & $0.87 \pm 0.11$ & $0.87 \pm 0.06$ & $0.98 \pm 0.08$ & $0.89 \pm 0.09$ & $0.93 \pm 0.11$ \\
\hline & Ex & $13.00 \pm 0.59 \#$ & $12.66 \pm 0.64 \#$ & $13.99 \pm 0.51 \#$ & $13.9 \pm 0.49 \#$ & $13.16 \pm 0.69 \#$ & $12.38 \pm 0.73 \#$ \\
\hline \multicolumn{8}{|c|}{ Ventilation Threshold } \\
\hline Work-rate, watt & & $125 \pm 6$ & $151 \pm 6^{*}+$ & $120 \pm 4$ & $136 \pm 5 *$ & $121 \pm 4.3$ & $122 \pm 6.8$ \\
\hline $\mathrm{V}_{\mathrm{E}}, \mathrm{L} / \mathrm{min}$ & & $44.8 \pm 2.3$ & $52.3 \pm 2.7 *$ & $43.5 \pm 1.9$ & $51.8 \pm 4.3 *$ & $45.2 \pm 1.8$ & $46.2 \pm 3.9$ \\
\hline $\mathrm{VO}_{2}, \mathrm{~mL} / \mathrm{min} / \mathrm{kg}$ & & $21.3 \pm 0.8$ & $26.4 \pm 1.0 * \dagger$ & $21.3 \pm 0.6$ & $23.3 \pm 0.5^{*}$ & $21.6 \pm 1.1$ & $21.2 \pm 1.2$ \\
\hline \multicolumn{7}{|c|}{ Maximal Exercise Performance } & $61.16 \pm 1.9$ \\
\hline Work-rate, watt & & $191 \pm 3$ & $223 \pm 5^{*}+$ & $189 \pm 4$ & $201 \pm 5^{*}$ & $188 \pm 5$ & $190 \pm 5$ \\
\hline $\mathrm{V}_{\mathrm{E}}, \mathrm{L} / \mathrm{min}$ & & $107.4 \pm 3.2$ & $118.8 \pm 2.5 *$ & $111.9 \pm 3.7$ & $115.3 \pm 2.2$ & $109.95 \pm 4.7$ & $108.3 \pm 4.3$ \\
\hline $\mathrm{VO}_{2}, \mathrm{~mL} / \mathrm{min} / \mathrm{kg}$ & & $35.7 \pm 1.1$ & $40.0 \pm 0.8^{*}$ & $35.2 \pm 0.7$ & $34.6 \pm 0.7$ & $34.1 \pm 1.0$ & $34.6 \pm 1.5$ \\
\hline OUES, unit & & $814 \pm 23$ & $886 \pm 20 *$ & $817 \pm 16$ & $829 \pm 24$ & $816 \pm 19$ & $825 \pm 20$ \\
\hline $\mathrm{V}_{\mathrm{E}}-\mathrm{VCO}_{2} \mathrm{~s}$ & Init & $36.8 \pm 1.5$ & $36.8 \pm 1.6$ & $37.6 \pm 1.9$ & $38.5 \pm 2.4$ & $35.7 \pm 1.6$ & $35.7 \pm 1$ \\
\hline
\end{tabular}

Values were mean \pm SEM. $\mathbf{H b}$, hemoglobin; $\mathbf{V}_{\mathbf{E}}$, minute ventilation; $\mathbf{V O}_{2}$, oxygen consumption; OUES, oxygen uptake efficiency slope; CCT, concentric cycling training; ECT, eccentric cycling training; CTL, control group. Pre, pre-intervention; Post, post-intervention; Rest, at rest; Ex, immediately after the GXT; \# $p<0.05$, Rest vs. Ex; ${ }^{*} p<0.05$, Pre vs. Post; $+p<0.05$, CCT vs. ECT.

\subsection{Pain Scale Scores, Heart Rate and Systolic Blood Pressure during the Training Period}

The CCT group had significantly higher levels of pain, $\mathrm{H}$, and SBP than the ECT group throughout the 6 week training period (Figure 2). Concerning the assessment of pain or soreness, the specific pain scale score was close to zero in both groups before each training session (Figure 2A). 

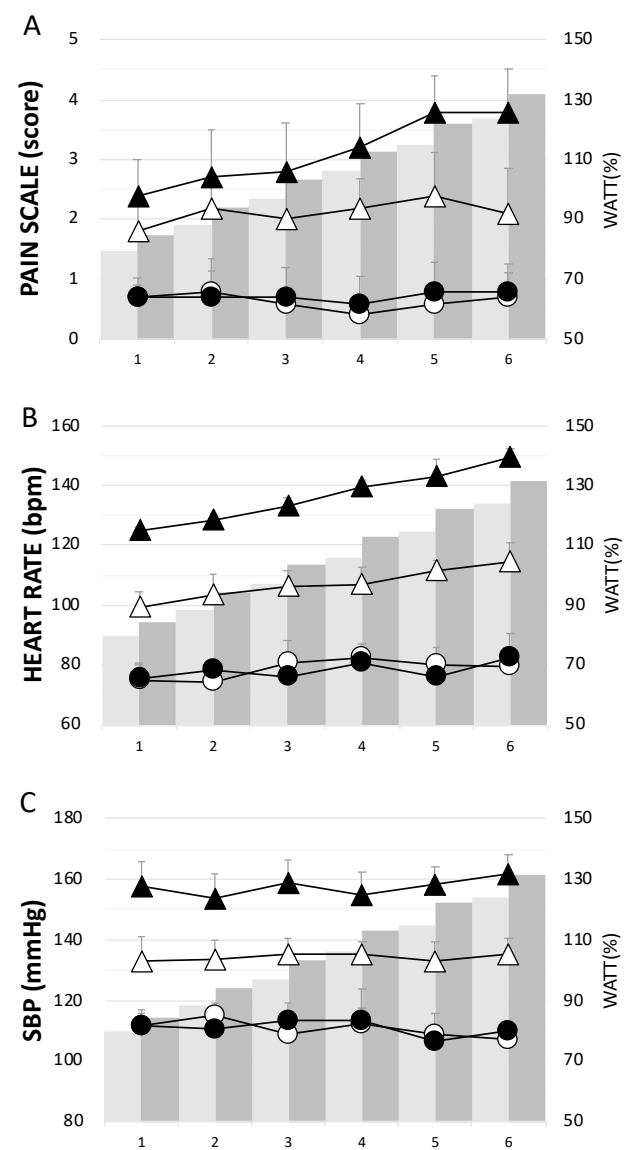

Figure 2. The physiological responses in each week during the training period. (A) pain scale score, (B) heart rate, and (C) systolic blood pressure. Whites- eccentric cycling training (ECT); Blacksconcentric cycling training (CCT); Dots-before training; Triangles-after training. Values were mean \pm SEM.

\subsection{Erythrocyte Senescence-Related Markers and Antioxidation Capacity}

The ratios of Ex to Rt in CD147 and CD47 cells were less than 1 before training, indicating enhanced senescence in erythrocytes due to an acute GXT. After the interventions, these ratios significantly increased to nearly 1 in response to a GXT (Figure 3A,B). Intracellular ROS levels were significantly increased after an acute GXT among the three groups; however, both training groups had lower ROS production related to the GXT after training (Figure 3C). Furthermore, as Figure 3D,F shows, a higher TBHP concentration induced greater ROS generation. Nevertheless, the two exercise regimens significantly diminished the extent of ROS generation under 50 and $100 \mathrm{mM}$ TBHP conditions (Figure 3D,E). No alteration was observed in the CTL group (Figure 3F). 


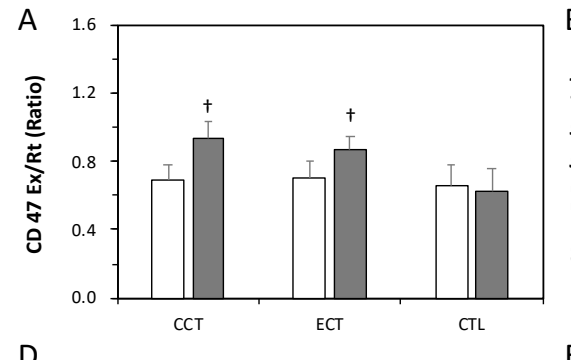

D

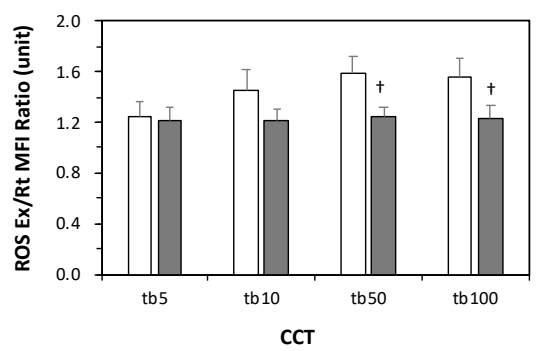

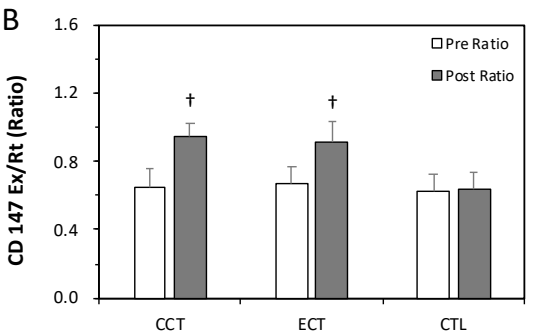

F

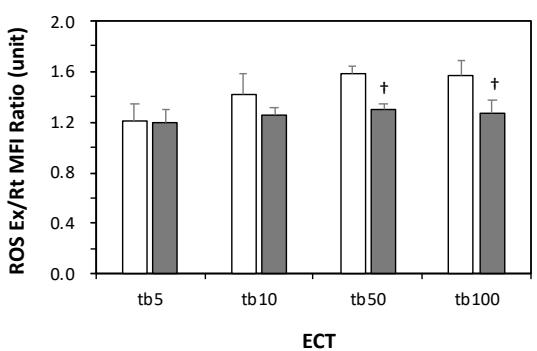

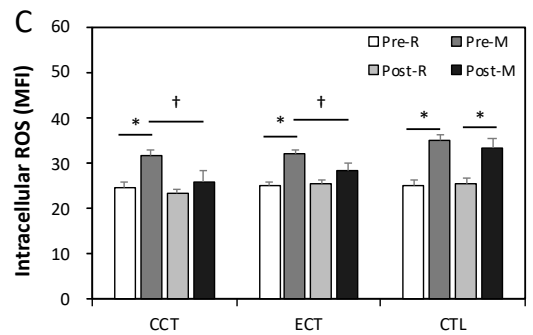

$\mathrm{F}$

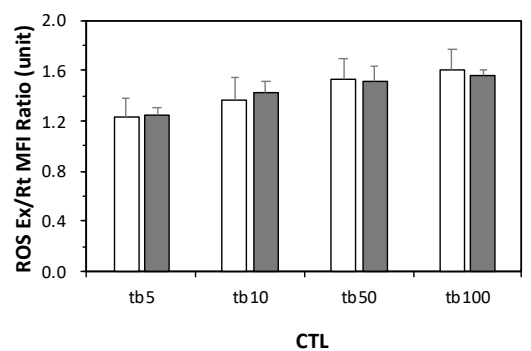

Figure 3. Effects of various ECT and CCT on the erythrocyte senescence-related biomarkers, intracellular reactive oxygen species (ROS) level and the ROS dose-response. (A) the ratio of post-graded exercise test (GXT) to pre-GXT in CD47, (B) the ratio of post-GXT to pre-GXT in CD147, (C) the intracellular ROS level among three groups; the ratio of Ex to Rt ROS response in erythrocytes treated with different concentrations of tert-butyl hydroperoxide (tb): (D) the CCT group, (E) the ECT group, and (F) the control (CTL) group. Pre, pre-intervention; Post, post-intervention; M or Ex, immediately after a GXT; R or Rt, at rest. ${ }^{*} p<0.05, \mathrm{R}$ vs. $\mathrm{M} ;+p<0.05$, Pre vs. Post. Values were mean $\pm \mathrm{SEM}$.

\subsection{Target Metabolite Analysis of Glycolysis and Pentose Phosphate Pathway Intermediates}

At baseline, the acute GXT showed greater glucose consumption and was accompanied by a series of unchanged levels of downstream metabolites until G3P (Figure 4A). The GSSG/GSH ratio significantly increased following an acute GXT, indicating an accumulation of oxidative stress. In addition, 2,3-BPG was depleted after the GXT.

Both glycolysis and the PPP were upregulated due to exercise training. Although no change was observed in the glucose level, the downstream metabolites were markedly elevated even under resting conditions. Interestingly, although 2,3-BPG was lower after training, the end product of glycolysis, lactate, was dramatically increased. The PPP flux was also facilitated, as evidenced by a decrease in 6PG and a constant GSSG/GSH ratio. Furthermore, the higher levels of Ru5P and GSH suggested a significant enhancement of GSH biosynthesis under stress. X5P and E4P are intermediates between the PPP and glycolysis, which was dramatically enhanced in both training groups.

In addition, the level of met-Hb was significantly increased by the acute GXT compared to the rest among the three groups, whereas the extent of elevation was diminished after training. The intracellular $\mathrm{pH}$ in erythrocytes did not change relative to the GXT before training, whereas both CCT and ECT lowered the $\mathrm{pH}$ value after 6 weeks (Figure 4B). 
A

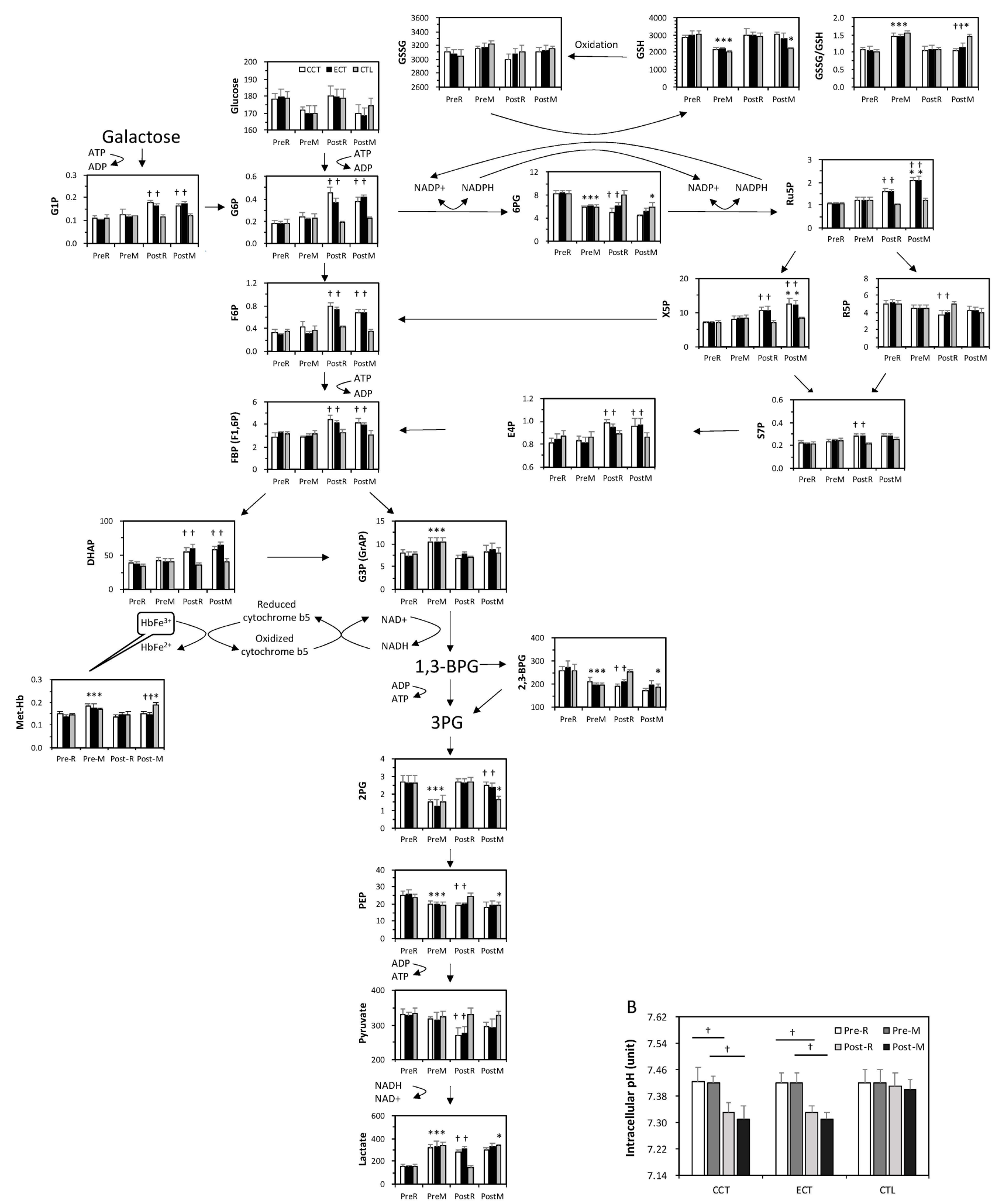

Figure 4. The target metabolite analysis of glycolysis and the pentose phosphate pathway intermediates in erythrocytes in ECT and CCT. (A) Levels of metabolites in pentose phosphate pathway and glycolytic pathway $(n=5)(\mathbf{B})$ the intracellular $\mathrm{pH}$ of erythrocytes. Pre, pre-intervention; Post, post-intervention; R, at rest; M, immediately after a GXT; ${ }^{*} p<0.05, \mathrm{R}$ vs. M; $+p<0.05$, Pre vs. Post. Values were mean \pm SEM. 


\subsection{Erythrocyte $\mathrm{O}_{2}$ Release Capacity in Normal Conditions}

As Figure 5A,F shows, oxygen was absorbed into the cell when isolated erythrocytes were added to the normoxia chamber, which produced a negative oxygen pressure difference $\left(\mathrm{O}_{2}\right.$ pressure-diff). Furthermore, this oxygen was released at lactate acid concentrations of 1 and $4 \mathrm{mM}$. After an acute GXT, the magnitudes of oxygen absorption and release were diminished (Figure $5 \mathrm{~A}, \mathrm{C}$ ) and coupled with a reduced flux velocity (Figure 5D,F). Following the interventions, both training groups exhibited a diminished $\mathrm{O}_{2}$ pressure-diff and velocity in 0 and $1 \mathrm{mM}$ lactate acid conditions at rest and even after the GXT. However, both CCT and ECT induced maintenance of these parameters at resting levels in the $4 \mathrm{mM}$ lactate acid condition (Figure 5C,F).

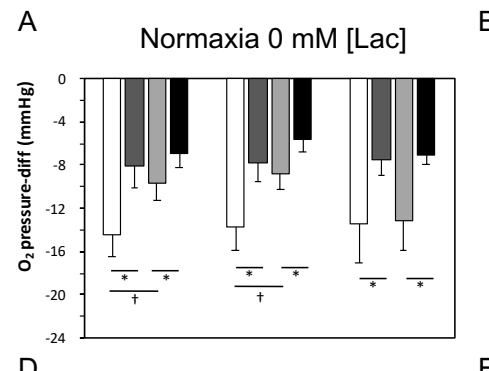

B

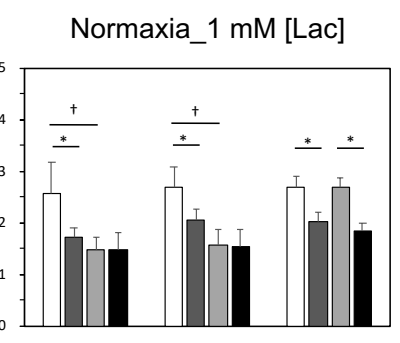

C

Normaxia_4 mM [Lac]

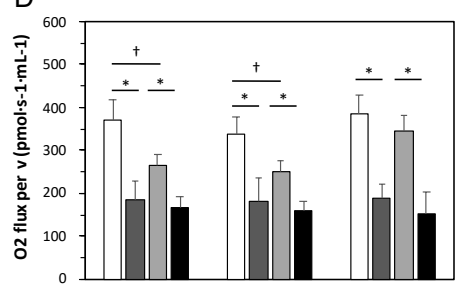

E
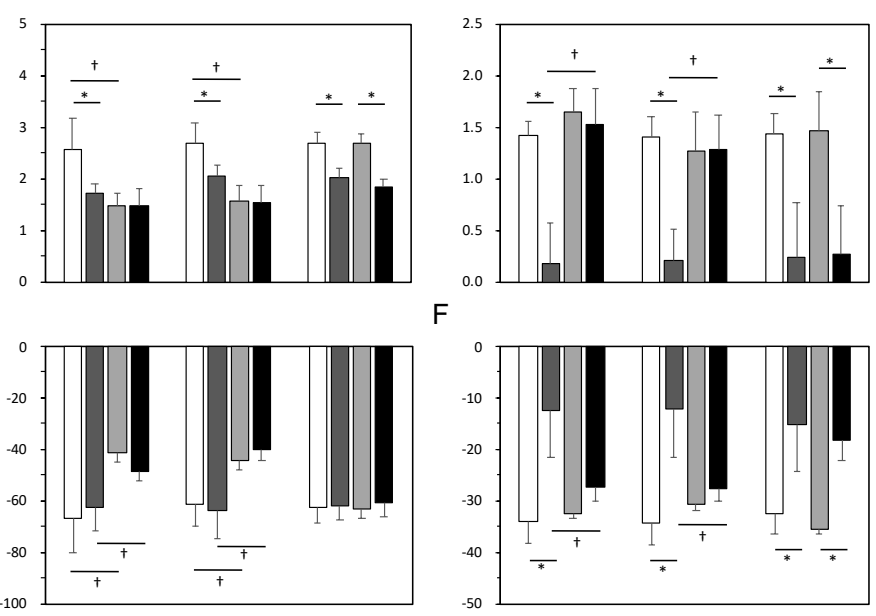

$\mathrm{F}$

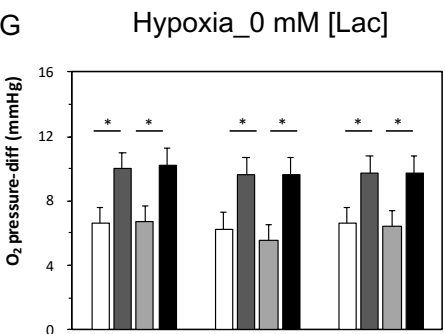

$\mathrm{H}$

Hypoxia_1 mM [Lac]
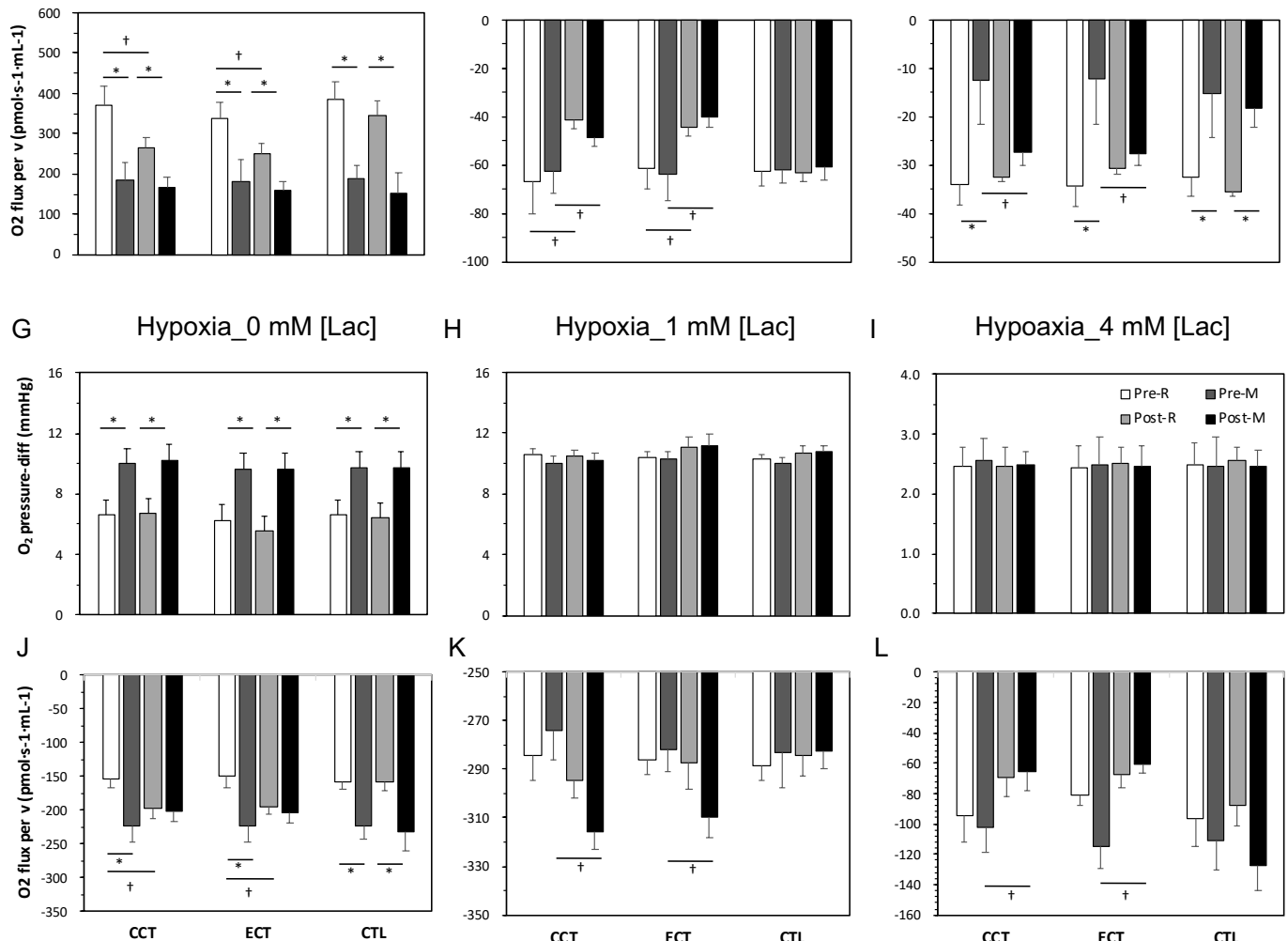

$\mathrm{K}$
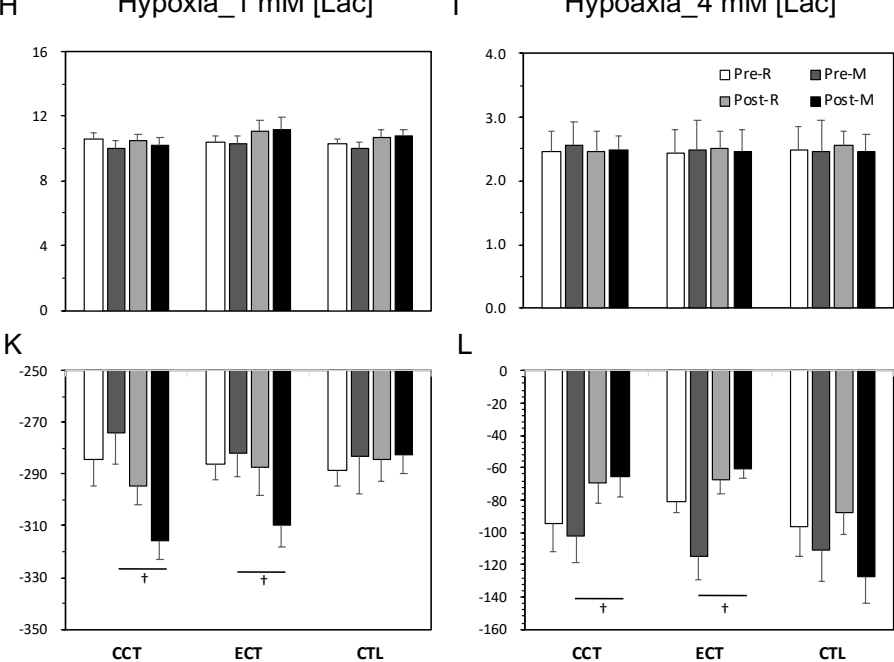

L

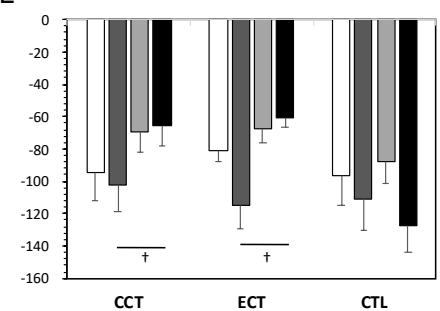

Figure 5. Measurement of oxygen release capacity of erythrocytes among three groups in normoxia and hypoxia conditions. Levels of $\mathrm{O}_{2}$ pressure-diff in normoxia condition: (A) at $0 \mathrm{mM}$ [lac], (B) at $1 \mathrm{mM}$ [lac], and (C) at $4 \mathrm{mM}$ [lac]; oxygen flux per volume in normoxia condition: (D) at $0 \mathrm{mM}$ [lac], (E) at $1 \mathrm{mM}$ [lac], and (F) at $4 \mathrm{mM}$ [lac]; levels of $\mathrm{O}_{2}$ pressure-diff in hypoxia condition: $(\mathbf{G})$ at $0 \mathrm{mM}$ [lac], (H) at $1 \mathrm{mM}$ [lac], and (I) at $4 \mathrm{mM}$ [lac]; oxygen flux per volume in hypoxia condition: (J) at $0 \mathrm{mM}$ [lac], (K) at $1 \mathrm{mM}$ [lac], and (L) at $4 \mathrm{mM}$ [lac]; Pre, pre-intervention; Post, post-intervention; R, at rest; M, immediately after a GXT; ${ }^{*} p<0.05, \mathrm{R}$ vs. $\mathrm{M} ;+p<0.05$, Pre vs. Post. Values were mean $\pm \mathrm{SEM}$.

\subsection{Erythrocyte $\mathrm{O}_{2}$ Release Capacity in Hypoxia Conditions}

$\mathrm{O}_{2}$ was released immediately $\left(\mathrm{O}_{2}\right.$ pressure-diff was positive) from erythrocytes when erythrocytes were added to the hypoxia chamber, and the magnitude of release was further 
augmented due to the GXT (Figure 5G,L). An enhanced release velocity was also noticed (Figure 5J). After training, although no alternation in the oxygen release amount was observed at rest or even after the GXT, a faster velocity was observed in both the CCT and ECT groups under 0, 1 and $4 \mathrm{mM}$ lactate acid (Figure 5J,K).

\subsection{Relationships between GSSG/GSH and Lactate/Pyruvate and between Intracellular $p H$ and Lactate Concentration}

Figure 6A shows that the increase in the GSSG/GSH ratio caused by the GXT was significantly linearly related to the augmented lactate/pyruvate ratio $(r=0.72, p<0.05)$. However, this correlation was blunted after training in both the CCT and ECT groups (Figure $6 \mathrm{~B}, r=0.29, p=0.12$ ). Furthermore, Figure $6 \mathrm{C}$ demonstrates that the lowered intracellular $\mathrm{pH}$ was moderately related to the greater lactate concentration $(r=-0.50$, $p<0.05)$.

A

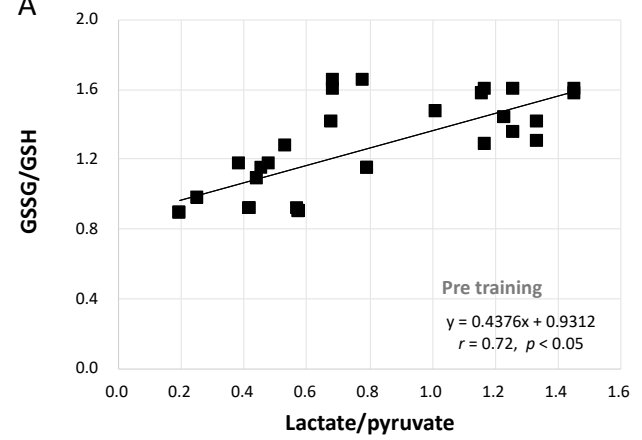

C

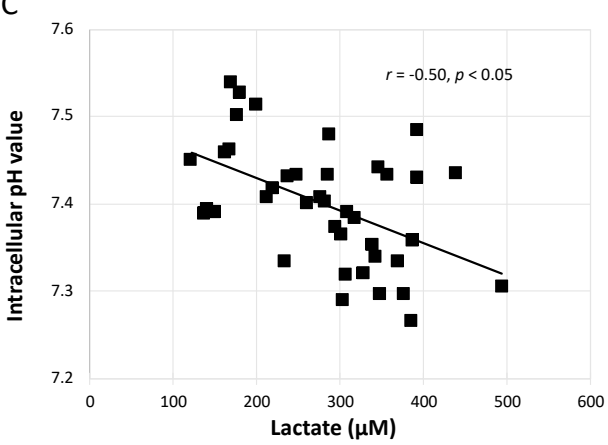

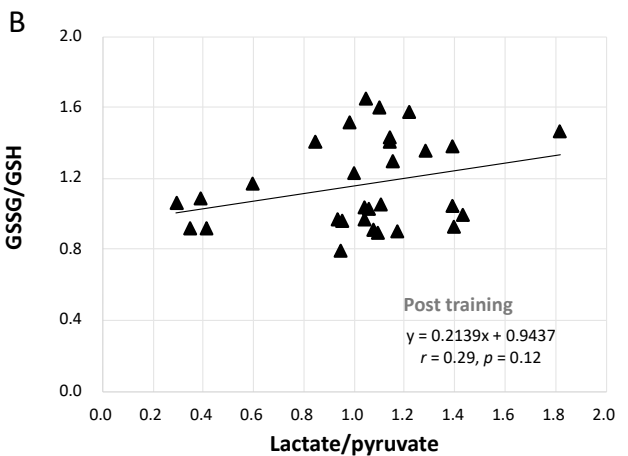

Figure 6. Correlation analysis between GSSG/GSH, lactate/pyruvate, intracellular $\mathrm{pH}$ value and lactate concentration. (A) relationship between GSSG/GSH and lactate/pyruvate before interventions, (B) relationship between GSSG/GSH and lactate/pyruvate after interventions, and (C) the correlation between intracellular $\mathrm{pH}$ value and lactate concentration. GSH, glutathione; GSSG, glutathione disulfide.

\section{Discussion}

Erythrocyte metabolism includes glycolytic pathways producing both energy and oxidation-reduction intermediates that support $\mathrm{O} 2$ transport and antioxidative capacity. This study is the first to demonstrate that both CCT and power-matched ECT not only ameliorate antioxidation capacity in erythrocytes but also significantly increase the flux of anaerobic glycolysis to facilitate oxygen release efficacy. We further elucidated that the reduced oxygen affinity is due to greater lactate synthesis and not to the production of 2,3-BPG. Although ECT did not result in significant improvement in $\mathrm{VO} 2$ max, the im-proved VT performance indicates the positive effect ECT has on the aerobic capacity of young and sedentary men.

Several studies have reported that blood GSSG and thus the GSH/GSSG ratio decrease in response to acute exercise, and regular exercise may increase antioxidative capacity [28]. After both CCT and ECT, neither the GSSG/GSH ratio nor GSH decreased due to the 
GXT, while enhanced anaerobic glycolysis provided more precursors to activate the PPP. In addition, the downstream X5P and E4P, from the PPP back to glycolysis, also increased after training, thus suggesting significant enhancement of GSH biosynthesis under stress. The linear relationship between GSSG/GSH and lactate/pyruvate was disrupted after training, which may be due to a changed dominance of energy or/and antioxidant production [29]. In addition, the oxidative environment leads to the production of $\mathrm{Fe}^{+}$(met- $\mathrm{Hb}$ ). To restore $\mathrm{Hb}$ function, met- $\mathrm{Hb}$ must be reduced mainly by $\mathrm{NADH}$-dependent cytochrome b5 reductase [30].

An interesting aspect of the metabolic pathways is that intracellular $\mathrm{pH}(\mathrm{pHi})$ regulates both the glycolytic pathway and the PPP. As with glycolysis, the optimum activity of the enzymes driving the PPP occurs at an alkaline pHi [31]. Generally, the presence of NADPH blocks PPP negative feedback control and shifts metabolism from the PPP to glycolysis, thus increasing the formation of $\mathrm{NAD}^{+}$[32]. Although NADH does not directly participate in the reduction of $\mathrm{Fe}^{+}$to $\mathrm{Fe}^{+}$in hemoglobin, it has the ultimate responsibility of providing the reducing power needed for such a reaction [33]. Under normal homeostasis in general, and especially in the case of the high glycolytic flux that is required during high-intensity exercise, lactate dehydrogenase oxidizes NADH back to $\mathrm{NAD}^{+}$in the conversion of pyruvate to lactate, thereby maintaining necessary levels of the cofactor for the continuation of glycolysis. Cyclists in the high-class group had a higher posttest lactate/pyruvate ratio, which is proportional to $\mathrm{NADH} / \mathrm{NAD}^{+}$and a marker of glycolytic capacity [34]. Additionally, it has been confirmed that high glucose levels induce in-creases in lactate and 6PG production in vitro and ensure a longer supply of energy sources, preventing the loss of GSH [35].

The blood lactate that was progressively elevated with exercise intensity further reduces local blood $\mathrm{pH}$ and thus enhances the Bohr effect to attenuate $\mathrm{O}_{2}$ affinity and facilitate $\mathrm{O}_{2}$ release [17]. In contrast, pulmonary $\mathrm{O}_{2}$ uptake is enhanced, but muscle unloading is hindered with high-affinity hemoglobin [36]. The capillary transit times were very limited; thus, the exchange speed is critical for evaluating the physiological fitness of erythrocytes [37]. Therefore, we developed a novel method for quantifying gas exchange in a constant number of erythrocytes and used it to assess the quality and quantity of $\mathrm{O}_{2}$ releasing capacity.

To clarify the oxygen release efficacy of erythrocytes, we measured the $\mathrm{PO}_{2}$, oxygen release/absorption velocity and acceleration under 0,1 , and $4 \mathrm{mM}$ lactic acid concentrations to mimic resting and near AT conditions, respectively. The $\mathrm{PO}_{2}$ increased (oxygen release) when lactic acid was added. Even with a smaller amount of $\mathrm{O}_{2}$ being supplied to the tissue, the efficacy was enhanced with faster acceleration and velocity, which indicates better efficiency for release. The improved release of oxygen efficacy at $4 \mathrm{mM}$ [lac] might be associated with improved cycling performance before reaching the anaerobic threshold. In addition, a diminished magnitude and velocity of $\mathrm{O}_{2}$ absorption after the acute GXT were noticed. We first speculated that this was a consequence of sufficiently oxygenated $\mathrm{Hb}$ after high oxygen demand activity or that this impaired quantity and quality may also be related to increases in oxidative and met- $\mathrm{Hb}$ levels after exhaustive exercise [38]. We further demonstrated an enhanced, strong correlation between lactate concentration and oxygen release magnitude and velocity under hypoxic conditions. The $\mathrm{O}_{2}$ affinity of athletes is lower than that of untrained subjects, which is consistent with our results [39]. Slow $\mathrm{VO}_{2}$ kinetics incur a high $\mathrm{O}_{2}$ deficit, usually resulting in poor exercise tolerance [40].

Lactic acid plays a vital indirect role in tissue $\mathrm{O}_{2}$ delivery apart from the direct allosteric interaction of lactate ions with $\mathrm{Hb}$ [41]. Lactic acid increases the Bohr shift via acidification as well as via liberation of $\mathrm{CO}_{2}$ [42]. Therefore, the lower affinity of hemoglobin for the $\mathrm{O}_{2}$ of erythrocytes in athletes at rest is maintained by the factor(s) dominating $\mathrm{pH}$ and lactate-driven regulation. Under heavy exercise (above the lactic acidosis threshold), acidification of muscle capillary blood by lactic acid accounts for virtually all of the oxygen unloaded from $\mathrm{Hb}$ [43]. 
Erythrocytes must be considered a potential storage site of lactate, storage of which leads to a greater gradient from the interstitial fluid to plasma. This mechanism improves the rate of release from muscle and ameliorates exercise performance [44]. However, a previous study demonstrated that the lactate distribution in erythrocytes and plasma after high-intensity running was not different between trained and untrained subjects. Hence, lactate uptake by erythrocytes cannot or can only in part be seen as a contributor to aerobic athletic performance [45]. Traditionally, a higher Bohr effect is supposed to be related to a higher 2,3-BPG in erythrocytes [46]. However, the generation of 2,3-BPG results in the overall production of ATP per mole of glucose is decreased to zero. Therefore, accumulation of 2,3-BPG leads to decreased production of 2,3-BPG by competitive feedback inhibition of di-phosphoglycerate mutase [47]. The relative ratio of 2,3-BPG synthase to 2,3-BPG phosphatase decreased dramatically with decreasing $\mathrm{pH}$ value [48]. The lactate effect even increased after 2,3-BPG depletion [49]. In this study, the presence of large lactate concentrations leading to lower $\mathrm{pH}$ values may effectively limit the production of 2,3BPG [50]. When the downstream enzymes of 2,3-BPG, such as pyruvate kinase and lactate dehydrogenase, maintained higher activities, the enzyme activities of other pathways were significantly repressed [48]. Therefore, this reversed flux of the 2,3-BPG shunt is crucial in maintaining the activities of the latter part of glycolysis and the production of ATP in the latter half of the storage period.

The results in this study clearly presented that, although both ECT and CCT ameliorate the erythrocyte antioxidant and oxygen releasing capacity, thus further delays the anaerobic threshold, yet only ECT has significantly less cardiopulmonary stress without undesirable fatigue or pain impact during the whole training period. Therefore, we suggest that ECT is preferred to those who have exercise intolerance or low physical activity, whereas CCT may be more feasible for those who have general physical activity to increase the ability to cope with the physical demands of daily activity. These findings provide a new suggestion on why ECT is worthy to further developed as a suitable training strategy in cardiopulmonary rehabilitation or the elderly.

A small sample size ( $n=12$ in each group) is a major limitation of this study. However, the results for aerobic capacity and the novel interpretation of the $\mathrm{O}_{2}$ release and antioxidative mechanisms in the metabolic pathways obtained from this investigation have high statistical power (0.862 to 1.000). We speculate that metabolic alteration of erythrocytes generates higher ATP concentrations followed by lactate production. We did not directly detect the ATP concentration because of the fast rate of ATP hydrolysis. Therefore, in this study, we indirectly inferred ATP demand by the lactate/pyruvate ratio. We did not see potential model alterations in $\mathrm{Hb}$ affinity as blood traverses the exercising muscles in accordance with local changes in temperature, $\mathrm{pHi}$, or $\mathrm{CO}_{2}$. There are certainly differences between and challenges with in vivo vs. in vitro measurements of $\mathrm{O}_{2}$ dissociation curve dynamics in both the lungs and muscles in response to variables such as temperature, $\mathrm{pHi}$, and 2,3-BPG. A few studies have shown that the additive effects of temperature and $\mathrm{pH}$ are responsible for shifting the $\mathrm{O}_{2}$ dissociation curve affinity, especially with prolonged exercise [51]. Additionally, the subjects tended to be young and healthy; thus, further clinical evidence is still required to extrapolate the present results to patients with hemorheological or hemodynamic disorders.

Although the glutathione system is a principal nonenzymic antioxidant system in erythrocytes yet, GSSG is rapidly formed, but it quickly disappears once the oxidative stimulus is interrupted; conversely, S-glutathionylated proteins (PSSGs) may be produced more slowly but are more durable [52]. Therefore, the PSSGs is a worthy parameter for further investigation [53]. In addition, although previously study suggested that exerciseinduced changes in the nonenzymatic glutathione system seem to be more effective in erythrocytes [54]. Nevertheless, many studies have indicated the activity of glutathione peroxidase (GPx) plays a key component in the antioxidant experiment [55], and regular cardiovascular training increased GPx activity in skeletal muscle [56]. Taking together, both PSSGs and the immunoblotting for GPx are very used to supply important information on 
the state of this antioxidant network in the future. To assess the reliabilities of biomarkers, metabolites and oxygen releasing capacity to exercise, the subjects $(n=5)$ in a prior study were tested twice at two-day intervals. Results of responses to exercise were highly reproducible from day to day. The intraclass correlation coefficients were from 0.811 to 0.954. Additionally, it requires separate analytical measurements for GSH and GSSG for accurate analysis and specific methodological procedures needed to detect samples [57]. Although the use of classical and well-validated in previous studies [26,58], techniques to perform our measurements, requiring immediate and complex processing of blood samples [59]. This limits the possibility of receiving samples from different centers to be analyzed. In the present study, we tested our participants at the same time of the day and asked them to record their nutritional intake and to maintain the same diet (data not shown). Thus, we assume that our results well represent the physical adaptations after exercise training. Importantly, other more adequate and precise methodologies should be considered in future studies [53].

\section{Conclusions}

This study presented evidence that both ECT and CCT simultaneously promote flux into the pentose phosphate pathway and anaerobic glycolysis pathway in response to overcoming accumulated oxidative stress and regulating internal $\mathrm{O}_{2}$ dissociation, respectively. The adaptations of the metabolite process not only increased the synthesis of GSH but also enhanced the production of lactate in glucose metabolism in trained erythrocytes. The lower intracellular $\mathrm{pH}$ value related to lactate, instead of 2,3-BPG, ameliorated the $\mathrm{O}_{2}$ release efficacy of erythrocytes under different $\mathrm{O}_{2}$ gradients. In addition, the reduced amount of met- $\mathrm{Hb}$ also contributed to the $\mathrm{O}_{2}$ release. The above experimental findings reflect many positive effects of both interventions and provide a novel interpretation of delayed anaerobic threshold by ameliorated $\mathrm{O}_{2}$ release and antioxidative mechanism in the metabolic pathway (Figure 7). Therefore, ECT is a feasible and promising exercise regimen that promotes a less cardiovascular stress way to exercise without undesirable fatigue impact and provides important implications for those who have exercise intolerance.

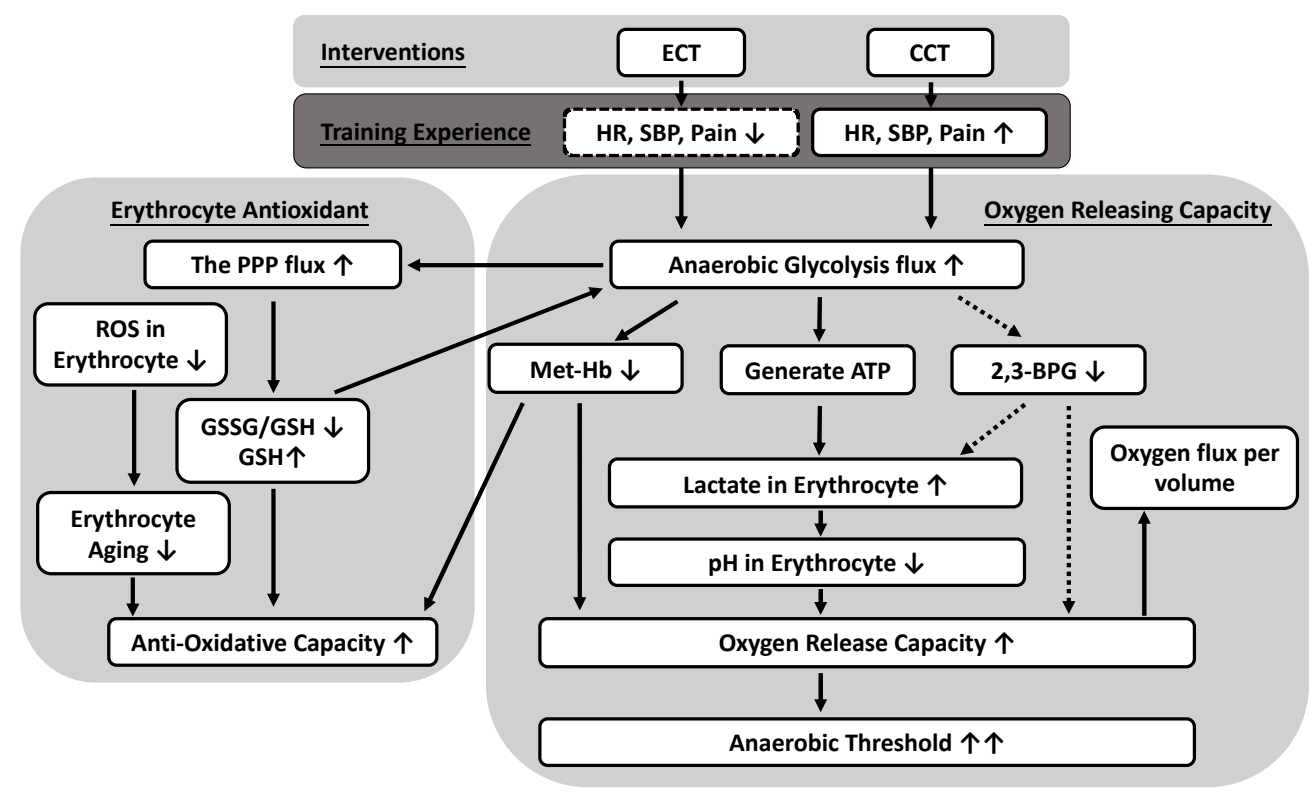

Figure 7. Possible mechanisms of anaerobic glycolytic pathways producing both oxygen releasing and antioxidative capacity caused by eccentric (ECT) and concentric cycling training (CCT). Both CCT and ECT at a given workload enhance an anaerobic glycolysis flux to ameliorate antioxidative capacity in erythrocytes, as well as significantly facilitate oxygen release efficacy. The reduced oxygen affinity is due to greater lactate synthesis and lower intracellular $\mathrm{pH}$, instead of the production of 2,3-BPG. Solid line: positive regulation; dotted line: negative regulation. 
Supplementary Materials: The following are available online at https:/ /www.mdpi.com/2076-392 1/10/2/285/s1, Figure S1: the scheme of testing oxygen release capacity in erythrocytes by using high-resolution respirometry.

Author Contributions: Conceptualization, J.-S.W. and Y.-C.H.; methodology, J.-S.W., Y.-C.H., H.-Y.T. and M.-L.C.; formal analysis, J.-S.W. and Y.-C.H.; investigation, Y.-C.H. and H.-Y.T.; writing-original draft preparation, Y.-C.H.; writing-review and editing, J.-S.W., Y.-C.H., H.-Y.T., M.-L.C., C.-Y.H. and K.-M.C.; supervision, J.-S.W.; funding acquisition, J.-S.W. and Y.-C.H. All authors have read and agreed to the published version of the manuscript.

Funding: This research was funded by the National Science Council of Taiwan, grant number NSC 108-2314-B-182 -039 -MY3 and 109-2314-B-468 -008 -MY2, and by the Chang Gung Medical Research Program, grant number CMRPD1J0222 and CMRPG2F0193.

Institutional Review Board Statement: The study was conducted according to the guidelines of the Declaration of Helsinki and approved by the Institutional Review Board of Chang Gung Memorial Hospital in Taiwan (protocol code 201900415A3 and 2019/5/17 approval).

Informed Consent Statement: Informed consent was obtained from all subjects involved in the study.

Data Availability Statement: All data is contained within the article.

Acknowledgments: The authors would like to thank the volunteers for their enthusiastic participation and assistance from medical writers, proof-readers and editors.

Conflicts of Interest: The authors declare no conflict of interest. The funders had no role in the design of the study; in the collection, analyses, or interpretation of data; in the writing of the manuscript, or in the decision to publish the results.

\section{References}

1. Hody, S.; Croisier, J.L.; Bury, T.; Rogister, B.; Leprince, P. Eccentric Muscle Contractions: Risks and Benefits. Front. Physiol. 2019, 10. [CrossRef]

2. Lastayo, P.C.; Reich, T.E.; Urquhart, M.; Hoppeler, H.; Lindstedt, S.L. Chronic eccentric exercise: Improvements in muscle strength can occur with little demand for oxygen. Am. J. Physiol. 1999, 276, 611-615. [CrossRef] [PubMed]

3. Haynes, A.; Linden, M.D.; Chasland, L.C.; Nosaka, K.; Maiorana, A.; Dawson, E.A.; Dembo, L.H.; Naylor, L.H.; Green, D.J. Acute impact of conventional and eccentric cycling on platelet and vascular function in patients with chronic heart failure. J. Appl. Physiol. 2017, 122, 1418-1424. [CrossRef]

4. Gault, M.L.; Willems, M.E. Aging, functional capacity and eccentric exercise training. Aging Dis. 2013, 4, 351-363. [CrossRef] [PubMed]

5. Nickel, R.; Troncoso, F.; Flores, O.; Gonzalez-Bartholin, R.; Mackay, K.; Diaz, O.; Jalon, M.; Peñailillo, L. Physiological response to eccentric and concentric cycling in patients with chronic obstructive pulmonary disease. Appl. Physiol. Nutr. Metab. 2020, 45, 1232-1237. [CrossRef] [PubMed]

6. Douglas, J.; Pearson, S.; Ross, A.; McGuigan, M. Chronic Adaptations to Eccentric Training: A Systematic Review. Sports Med. 2017, 47, 917-941. [CrossRef]

7. Peñailillo, L.; Mackay, K.; Gonzalez, R.; Valladares, D.; Contreras-Ferrat, A.; Zbinden-Foncea, H.; Nosaka, K. Effects of Eccentric and Concentric Cycling on Markers of Oxidative Stress and Inflammation in Elderly. Med. Sci. Sports Exerc. 2018, 50, 518. [CrossRef]

8. Peñailillo, L.; Blazevich, A.; Nosaka, K. Energy expenditure and substrate oxidation during and after eccentric cycling. Eur. J. Appl. Physiol. 2014, 114, 805-814. [CrossRef]

9. Julian, V.; Thivel, D.; Miguet, M.; Pereira, B.; Costes, F.; Coudeyre, E.; Duclos, M.; Richard, R. Eccentric cycling is more efficient in reducing fat mass than concentric cycling in adolescents with obesity. Scand. J. Med. Sci. Sports 2019, 29, 4-15. [CrossRef] [PubMed]

10. Aoi, W.; Naito, Y.; Yoshikawa, T. Role of oxidative stress in impaired insulin signaling associated with exercise-induced muscle damage. Free Radic. Biol. Med. 2013, 65, 1265-1272. [CrossRef] [PubMed]

11. Barreto, R.V.; de Lima, L.C.R.; Denadai, B.S. Moving forward with backward pedaling: A review on eccentric cycling. Eur. J. Appl. Physiol. 2021, 121, 381-407. [CrossRef] [PubMed]

12. Mohanty, J.G.; Nagababu, E.; Rifkind, J.M. Red blood cell oxidative stress impairs oxygen delivery and induces red blood cell aging. Front. Physiol. 2014, 5, 84. [CrossRef]

13. Laaksonen, D.E.; Atalay, M.; Niskanen, L.; Uusitupa, M.; Hanninen, O.; Sen, C.K. Blood glutathione homeostasis as a determinant of resting and exercise-induced oxidative stress in young men. Redox Rep. Commun. Free Radic. Res. 1999, 4, 53-59. [CrossRef] 
14. Marzatico, F.; Pansarasa, O.; Bertorelli, L.; Somenzini, L.; Della Valle, G. Blood free radical antioxidant enzymes and lipid peroxides following long-distance and lactacidemic performances in highly trained aerobic and sprint athletes. J. Sports Med. Phys. Fit. 1997, 37, 235-239.

15. González-Bartholin, R.; Mackay, K.; Valladares, D.; Zbinden-Foncea, H.; Nosaka, K.; Peñailillo, L. Changes in oxidative stress, inflammation and muscle damage markers following eccentric versus concentric cycling in older adults. Eur. J. Appl. Physiol. 2019, 119, 2301-2312. [CrossRef] [PubMed]

16. Elmer, S.J.; McDaniel, J.; Martin, J.C. Alterations in neuromuscular function and perceptual responses following acute eccentric cycling exercise. Eur. J. Appl. Physiol. 2010, 110, 1225-1233. [CrossRef] [PubMed]

17. Böning, D.; Hollnagel, C.; Boecker, A.; Göke, S. Bohr shift by lactic acid and the supply of O2 to skeletal muscle. Respir. Physiol. 1991, 85, 231-243. [CrossRef]

18. Mairbaurl, H. Red blood cells in sports: Effects of exercise and training on oxygen supply by red blood cells. Front. Physiol. 2013, 4, 332. [CrossRef]

19. Chaves, N.A.; Alegria, T.G.P.; Dantas, L.S.; Netto, L.E.S.; Miyamoto, S.; Bonini Domingos, C.R.; da Silva, D.G.H. Impaired antioxidant capacity causes a disruption of metabolic homeostasis in sickle erythrocytes. Free Radic. Biol. Med. 2019, 141, 34-46. [CrossRef]

20. Rogers, S.C.; Said, A.; Corcuera, D.; McLaughlin, D.; Kell, P.; Doctor, A. Hypoxia limits antioxidant capacity in red blood cells by altering glycolytic pathway dominance. FASEB J. 2009, 23, 3159-3170. [CrossRef] [PubMed]

21. Brown, S.P.; Keith, W.B. The effects of acute exercise on levels of erythrocyte 2,3-bisphosphoglycerate: A brief review. J. Sports Sci. 1993, 11, 479-484. [CrossRef]

22. Guesnon, P.; Poyart, C.; Bursaux, E.; Bohn, B. The binding of lactate and chloride ions to human adult hemoglobin. Respir. Physiol. 1979, 38, 115-129. [CrossRef]

23. Roth, S.; Gmünder, H.; Dröge, W. Regulation of intracellular glutathione levels and lymphocyte functions by lactate. Cell. Immunol. 1991, 136, 95-104. [CrossRef]

24. American College of Sports Medicine. ACSM's Guidelines for Exercise Testing and Prescription, 10th ed.; Lippincott Williams \& Wilkins: Philadelphia, PA, USA, 2017.

25. Chou, S.L.; Huang, Y.C.; Fu, T.C.; Hsu, C.C.; Wang, J.S. Cycling Exercise Training Alleviates Hypoxia-Impaired Erythrocyte Rheology. Med. Sci. Sports Exerc. 2016, 48, 57-65. [CrossRef]

26. Tang, H.Y.; Ho, H.Y.; Wu, P.R.; Chen, S.H.; Kuypers, F.A.; Cheng, M.L.; Chiu, D.T.L. Inability to Maintain GSH Pool in G6PDDeficient Red Cells Causes Futile AMPK Activation and Irreversible Metabolic Disturbance. Antioxid. Redox Sign. 2015, 22, 744-759. [CrossRef]

27. McDonald, J.G.; Smith, D.D.; Stiles, A.R.; Russell, D.W. A comprehensive method for extraction and quantitative analysis of sterols and secosteroids from human plasma. J. Lipid Res. 2012, 53, 1399-1409. [CrossRef] [PubMed]

28. Kawamura, T.; Muraoka, I. Exercise-Induced Oxidative Stress and the Effects of Antioxidant Intake from a Physiological Viewpoint. Antioxidants 2018, 7, 119. [CrossRef]

29. Sastre, J.; Asensi, M.; Gasco, E.; Pallardo, F.V.; Ferrero, J.A.; Furukawa, T.; Vina, J. Exhaustive physical exercise causes oxidation of glutathione status in blood: Prevention by antioxidant administration. Am. J. Physiol. 1992, 263, 992-995. [CrossRef] [PubMed]

30. Maeda, S.; Kobori, H.; Tanigawa, M.; Sato, K.; Yubisui, T.; Hori, H.; Nagata, Y. Methemoglobin reduction by NADH-cytochrome b(5) reductase in Propsilocerus akamusi larvae. Comp. Biochem. Physiol. Part B Biochem. Mol. Biol. 2015, 185, 54-61. [CrossRef]

31. Alfarouk, K.O.; Ahmed, S.B.M.; Elliott, R.L.; Benoit, A.; Alqahtani, S.S.; Ibrahim, M.E.; Bashir, A.H.H.; Alhoufie, S.T.S.; Elhassan, G.O.; Wales, C.C.; et al. The Pentose Phosphate Pathway Dynamics in Cancer and Its Dependency on Intracellular pH. Metabolites 2020, 10, 285. [CrossRef]

32. Alfarouk, K.O.; Muddathir, A.K.; Shayoub, M.E.A. Tumor Acidity as Evolutionary Spite. Cancers 2011, 3, 408-414. [CrossRef]

33. Ho, H.Y.; Cheng, M.L.; Chiu, D.T. Glucose-6-phosphate dehydrogenase-from oxidative stress to cellular functions and degenerative diseases. Redox Rep. Commun. Free Radic. Res. 2007, 12, 109-118. [CrossRef]

34. San-Millán, I.; Stefanoni, D.; Martinez, J.L.; Hansen, K.C.; D’Alessandro, A.; Nemkov, T. Metabolomics of Endurance Capacity in World Tour Professional Cyclists. Front. Physiol. 2020, 11, 578. [CrossRef]

35. Viskupicova, J.; Blaskovic, D.; Galiniak, S.; Soszyński, M.; Bartosz, G.; Horakova, L.; Sadowska-Bartosz, I. Effect of high glucose concentrations on human erythrocytes in vitro. Redox Biol. 2015, 5, 381-387. [CrossRef] [PubMed]

36. Dominelli, P.B.; Wiggins, C.C.; Baker, S.E.; Shepherd, J.R.A.; Roberts, S.K.; Roy, T.K.; Curry, T.B.; Hoyer, J.D.; Oliveira, J.L.; Joyner, M.J. Influence of high affinity haemoglobin on the response to normoxic and hypoxic exercise. J. Physiol. 2020, 598, 1475-1490. [CrossRef]

37. Richardson, S.L.; Hulikova, A.; Proven, M.; Hipkiss, R.; Akanni, M.; Roy, N.B.A.; Swietach, P. Single-cell $\mathrm{O}_{2}$ exchange imaging shows that cytoplasmic diffusion is a dominant barrier to efficient gas transport in red blood cells. Proc. Natl. Acad. Sci. USA 2020, 117, 10067. [CrossRef]

38. Xiong, Y.; Xiong, Y.; Wang, Y.; Zhao, Y.; Li, Y.; Ren, Y.; Wang, R.; Zhao, M.; Hao, Y.; Liu, H.; et al. Exhaustive-exercise-induced oxidative stress alteration of erythrocyte oxygen release capacity. Canad. J. Physiol. Pharmacol. 2018, 96, 953-962. [CrossRef]

39. Makhro, A.; Haider, T.; Wang, J.; Bogdanov, N.; Steffen, P.; Wagner, C.; Meyer, T.; Gassmann, M.; Hecksteden, A.; Kaestner, L.; et al. Comparing the impact of an acute exercise bout on plasma amino acid composition, intraerythrocytic $\mathrm{Ca}^{+} \mathrm{handling}$, and red cell function in athletes and untrained subjects. Cell Calcium 2016, 60, 235-244. [CrossRef] 
40. Calbet, J.; González-Alonso, J.; Helge, J.; Søndergaard, H.; Munch-Andersen, T.; Saltin, B.; Boushel, R. Central and peripheral hemodynamics in exercising humans: Leg vs arm exercise. Scand. J. Med. Sci. Sports 2015, 25, 144-157. [CrossRef] [PubMed]

41. Robergs, R.A.; Ghiasvand, F.; Parker, D. Biochemistry of exercise-induced metabolic acidosis. Am. J. Physiol. Regul. Integr. Comp. Physiol. 2004, 287, 502-516. [CrossRef]

42. Jensen, F.B. Red blood cell $\mathrm{pH}$, the Bohr effect, and other oxygenation-linked phenomena in blood $\mathrm{O}_{2}$ and $\mathrm{CO}_{2}$ transport. Acta Physiol. Scand. 2004, 182, 215-227. [CrossRef] [PubMed]

43. Stringer, W.; Wasserman, K.; Casaburi, R.; Porszasz, J.; Maehara, K.; French, W. Lactic acidosis as a facilitator of oxyhemoglobin dissociation during exercise. J. Appl. Physiol. 1994, 76, 1462-1467. [CrossRef] [PubMed]

44. Connes, P.; Caillaud, C.; Mercier, J.; Bouix, D.; Casties, J.F. Injections of recombinant human erythropoietin increases lactate influx into erythrocytes. J. Appl. Physiol. 2004, 97, 326-332. [CrossRef] [PubMed]

45. Tomschi, F.; Bizjak, D.A.; Predel, H.-G.; Bloch, W.; Grau, M. Lactate distribution in red blood cells and plasma after a high intensity running exercise in aerobically trained and untrained subjects. J. Hum. Sport Exerc. 2018, 13, 384-392. [CrossRef]

46. Mairbaurl, H.; Humpeler, E.; Schwaberger, G.; Pessenhofer, H. Training-dependent changes of red cell density and erythrocytic oxygen transport. J. Appl. Physiol. 1983, 55, 1403-1407. [CrossRef] [PubMed]

47. Oslund, R.C.; Su, X.; Haugbro, M.; Kee, J.-M.; Esposito, M.; David, Y.; Wang, B.; Ge, E.; Perlman, D.H.; Kang, Y.; et al. Bisphosphoglycerate mutase controls serine pathway flux via 3-phosphoglycerate. Nat. Chem. Biol. 2017, 13, $1081-1087$. [CrossRef]

48. Nishino, T.; Yachie-Kinoshita, A.; Hirayama, A.; Soga, T.; Suematsu, M.; Tomita, M. Dynamic simulation and metabolome analysis of long-term erythrocyte storage in adenine-guanosine solution. PLoS ONE 2013, 8, e71060. [CrossRef] [PubMed]

49. Böning, D.; Schünemann, H.J.; Maassen, N.; Busse, M.W. Reduction of oxylabile CO2 in human blood by lactate. J. Appl. Physiol. 1993, 74, 710-714. [CrossRef]

50. Mairbäurl, H.; Schobersberger, W.; Hasibeder, W.; Schwaberger, G.; Gaesser, G.; Tanaka, K.R. Regulation of red cell 2,3-DPG and $\mathrm{Hb}_{-} \mathrm{O}_{2}$-affinity during acute exercise. Eur. J. Appl. Physiol. Occup. Physiol. 1986, 55, 174-180. [CrossRef] [PubMed]

51. Dempsey, J.A.; Wagner, P.D. Exercise-induced arterial hypoxemia. J. Appl. Physiol. 1999, 87, 1997-2006. [CrossRef]

52. Rossi, R.; Milzani, A.; Dalle-Donne, I.; Giannerini, F.; Giustarini, D.; Lusini, L.; Colombo, R.; Di Simplicio, P. Different metabolizing ability of thiol reactants in human and rat blood: Biochemical and pharmacological implications. J. Biol. Chem. 2001, 276, 7004-7010. [CrossRef]

53. Giustarini, D.; Colombo, G.; Garavaglia, M.L.; Astori, E.; Portinaro, N.M.; Reggiani, F.; Badalamenti, S.; Aloisi, A.M.; Santucci, A.; Rossi, R.; et al. Assessment of glutathione/glutathione disulphide ratio and S-glutathionylated proteins in human blood, solid tissues, and cultured cells. Free Radic. Biol. Med. 2017, 112, 360-375. [CrossRef] [PubMed]

54. Unt, E.; Kairane, C.; Vaher, I.; Zilmer, M. Red blood cell and whole blood glutathione redox status in endurance-trained men following a ski marathon. J. Sports Sci. Med. 2008, 7, 344-349. [PubMed]

55. Li, X.D.; Sun, G.F.; Zhu, W.B.; Wang, Y.H. Effects of high intensity exhaustive exercise on SOD, MDA, and NO levels in rats with knee osteoarthritis. Genet. Mol. Res. GMR 2015, 14, 12367-12376. [CrossRef] [PubMed]

56. Erbs, S.; Höllriegel, R.; Linke, A.; Beck Ephraim, B.; Adams, V.; Gielen, S.; Möbius-Winkler, S.; Sandri, M.; Kränkel, N.; Hambrecht, R.; et al. Exercise Training in Patients with Advanced Chronic Heart Failure (NYHA IIIb) Promotes Restoration of Peripheral Vasomotor Function, Induction of Endogenous Regeneration, and Improvement of Left Ventricular Function. Circ. Heart Fail. 2010, 3, 486-494. [CrossRef] [PubMed]

57. Stempak, D.; Dallas, S.; Klein, J.; Bendayan, R.; Koren, G.; Baruchel, S. Glutathione stability in whole blood: Effects of various deproteinizing acids. Ther. Drug Monit. 2001, 23, 542-549. [CrossRef]

58. Cheng, M.-L.; Lin, J.-F.; Huang, C.-Y.; Li, G.-J.; Shih, L.-M.; Chiu, D.T.-Y.; Ho, H.-Y. Sedoheptulose-1,7-bisphospate Accumulation and Metabolic Anomalies in Hepatoma Cells Exposed to Oxidative Stress. Oxid. Med. Cell. Longev. 2019, 5913635. [CrossRef]

59. Gutteridge, B.H.J.M.C. Free Radicals in Biology and Medicine, 5th ed.; Oxford University Press Inc.: New York, NY, USA, 2015. 